Data Descriptor

\title{
Forty Years of the Applications of Stark Broadening Data Determined with the Modified Semiempirical Method
}

\author{
Milan S. Dimitrijević(i) \\ Astronomical Observatory, Volgina 7, 11060 Belgrade, Serbia; mdimitrijevic@aob.rs; Tel.: +381-64-297-8021 \\ Received: 25 July 2020; Accepted: 17 August 2020; Published: 23 August 2020 \\ check for
updates
}

\begin{abstract}
The aim of this paper is to analyze the various uses of Stark broadening data for non-hydrogenic lines emitted from plasma, obtained with the modified semiempirical method formulated 40 years ago (1980), which are continuously implemented in the STARK-B database. In such a way one can identify research fields where they are applied and better see the needs of users in order to better plan future work. This is done by analysis of citations of the modified semiempirical method and the corresponding data in international scientific journals, excluding cases when they are used for comparison with other experimental or theoretical Stark broadening data or for development of the theory of Stark broadening. On the basis of our analysis, one can conclude that the principal applications of such data are in astronomy (white dwarfs, A and B stars, and opacity), investigations of laser produced plasmas, laser design and optimization and their applications in industry and technology (ablation, laser melting, deposition, plasma during electrolytic oxidation, laser micro sintering), as well as for the determination of radiative properties of various plasmas, plasma diagnostics, and investigations of regularities and systematic trends of Stark broadening parameters.
\end{abstract}

Dataset: Stark broadening parameters for isolated lines of non-hydrogenic atoms and ions calculated by using the impact semiclassical perturbation method and modified semiempirical method are available online in the STARK-B database at https://stark-b.obspm.fr/. This is one of 38 databases that can be searched and through the Virtual Atomic and Molecular Data Center (VAMDC) at https://portal.vamdc.eu/vamdc_portal/home.seam

Dataset License: CC BY 4.0.

Keywords: atomic data; Stark broadening; line profiles

\section{Introduction}

Stark broadening of spectral lines in plasmas is the broadening under the influence of the electric field of particles surrounding an emitter or absorber [1,2]. For isolated non-hydrogenic lines, if the impact approximation [1] is valid, a line profile is characterized by full width at half intensity maximum (FWHM-W) and shift d, so-called Stark broadening parameters. Such parameters may be useful for different problems in astrophysical, laboratory, laser produced, fusion, and technological plasma investigation, modeling, and analysis. For example, in astrophysics, with spectrographs on board or on class $10 \mathrm{~m}$ and larger terrestrial telescopes, a huge quantity of spectroscopic data with excellent resolution, for all kinds of space plasmas within various spectral ranges, is collecting. There is a consequent interest for a very extensive list of different atomic data for various atoms and ions, as well as for the corresponding database increases, because of the need for interpretation, synthesis, and analysis 
of high resolution spectra with well-resolved line profiles, in particular that obtained during different space missions, for example the Far Ultraviolet Spectroscopy Explorer (FUSE), the Goddard High Resolution Spectrograph (GHRS) on the Hubble Space Telescope, and many others.

Conditions in astrophysical plasmas, where the Stark broadening data are of interest, are incomparably more various. The illustration of such extreme temperature and electron density ranges of interest in astrophysics is the plasma in the clouds of interstellar molecular hydrogen, with temperatures around $30 \mathrm{~K}$ and electron densities of 1-5 electrons $/ \mathrm{cm}^{3}$. Here, electrons in distant orbit with principal quantum number values of several hundred or larger are weakly bounded with the core, so that even very weak electric microfields can have a non-negligible influence. They are deexciting in cascades emitting in the radio domain, lines with profiles influenced by Stark broadening. This broadening mechanism may be dominant in white dwarf atmospheres and may contribute to the line profile of hot stars of A and B type.

In the cases, when this broadening mechanism cannot be neglected, Stark broadening parameters for different spectral lines are needed for synthesis, analysis, and interpretation of stellar spectra; investigations of radiative transfer through stellar atmospheres; determination of chemical abundances; modeling and investigation of subphotospheric layers; stellar opacity determination; radiative acceleration in stellar atmospheres; nucleosynthesis; etc.

Stark broadening data are needed and for laboratory plasma diagnostics, laser produced plasma and inertial fusion plasma investigation and modeling, the investigations of lasers, and for research of different technological plasmas, such as those used in laser welding and piercing, as well as for light sources.

Different calculation methods of Stark broadening parameters for non-hydrogenic lines exist. The most advanced is the quantum mechanical strong coupling approach (see, e.g., [3]), but in many cases, the impact semiclassical perturbation method $[4,5]$ is the most efficient for Stark broadening parameter calculations, providing the largest set of existing theoretical results implemented in the STARK-B database [6-8]. For complex atoms, where there are not enough data for full semiclassical calculations, the modified semiempirical theory [9-11] has been used, and the obtained data are also implemented in the STARK-B database.

As of 14th of July 2020, Stark line widths and in some cases shifts of spectral lines of the following non-hydrogenic emitters, obtained by using the modified semiempirical (MSE) method, have been implemented in the STARK-B database:

Ag II, Ar II, As II, Au II, Ba II, Bi II, Br II, Ca II, Cd II, Co II, Eu II, Fe II, Ga II, I II, Kr II, La II, Mg II, Mn II, N II, Nd II, O II, Pt II, Ra II, S II, Sb II, Sc II, Si II, Sr II, Ti II, V II, Xe II, Y II, Zn II, Zr II,

Al III, Ar III, As III, B III, Be III, Bi III, C III, Cl III, Cu III, Eu III, F III, Ga III, Ge III, Kr III, La III, Mg III, N III, Na III, Nb III, Ne III, O III, P III, S III, Se III, Si III, Sn III, Sr III, Ti III, V III, Zn III, Zr III,

Ar IV, B IV, C IV, Cl IV, Cu IV, Ge IV, Mg IV, N IV, Ne IV, O IV, P IV, S IV, Si IV, V IV,

Al V, C V, F V, Ne V, O V, Si V,

Cl VI, F VI, N VI, Na VI, Ne VI, P VI, Si VI,

Ne VII, Ne VIII, Si XI.

The modified semiempirical method was formulated 40 years ago, in 1980. The obtained Stark broadening data for non-hydrogenic ions as well as the method have been used and cited many hundred times for various applications and investigations. The set of Stark broadening parameters for non-hydrogenic ions, accumulated during the 40 years since the first publication, allows an examination how and for what purposes such data and the MSE method have been used. Such analysis shows not only the possibilities of applicability of this set of data, continuously implemented in the STARK-B database, but also that the needs of its principal users could be seen and understood, so that the presentation of results as well as the plans for future calculations and research could be adapted to the needs of the users of these data. We exclude from this analysis numerous citations where these data and this method have been used for comparison with experimental or theoretical Stark broadening data or cited in different reviews on Stark broadening, doctoral theses, or conference proceedings and 
local journals and consider only different applications in other research fields in articles published in different international journals.

\section{Modified Semiempirical Method}

Stark full width at half maximum (FHWM) of an isolated non-hydrogenic ion line, within the modified semiempirical (MSE) method, [9-11] is:

$$
\begin{gathered}
W_{M S E}=N \frac{4 \pi \hbar^{2}}{3 c m^{2}}\left(\frac{2 m}{\pi k T}\right)^{1 / 2} \frac{\lambda^{2}}{3^{1 / 2}}\left[\sum_{l_{i} \pm 1} \sum_{L_{i \prime} l_{i \prime}} R_{l_{i}, l_{i} \pm 1}^{2} \tilde{g}\left(x_{l_{i}, l_{i} \pm 1}\right)+\sum_{l_{f} \pm 1} \sum_{L_{f}, J_{f \prime}} R_{l_{f}, l_{f} \pm 1}^{2} \tilde{g}\left(x_{l_{f}, l_{f} \pm 1}\right)\right. \\
\left.\left.+\left(\sum_{i \prime} R_{i i \prime}^{2}\right)_{\Delta n \neq 0} g\left(x_{n_{i}, n_{i}+1}\right)+\left(\sum_{f} R_{f f}^{2}\right)\right]_{\Delta n \neq 0} g\left(x_{n_{f}, n_{f}+1}\right)\right]
\end{gathered}
$$

and the corresponding Stark line shift is:

$$
\begin{aligned}
& d_{M S E}=N \frac{2 \pi \hbar^{2}}{3 c m^{2}}\left(\frac{2 m}{\pi k T}\right)^{1 / 2} \frac{\lambda^{2}}{3^{1 / 2}}\left[\sum_{L_{i} J_{i}} \sigma_{J_{i}} J_{i} R_{l_{i}, l_{i}+1}^{2} \tilde{g_{s h}}\left(x_{l_{i}, l_{i}+1}\right)\right. \\
& -\sum_{L_{i^{\prime}} J_{i^{\prime}}} \sigma_{J_{i} j_{i^{\prime}}} R_{l_{i}, l_{i}-1}^{2} \tilde{g_{s h}}\left(x_{l_{i}, l_{i}-1}\right)-\sum_{L_{f}, J_{f},}^{L_{i, J_{i}}} \sigma_{J_{f} J_{f}} R_{l_{f}, l_{f}+1}^{2} \tilde{g_{s h}}\left(x_{l_{f}, l_{f}+1}\right) \\
& +\sum_{L_{f^{\prime}} J_{f^{\prime}}} \sigma_{J_{f} J_{f^{\prime}}} R_{l_{f}, l_{f}-1}^{2} \tilde{g_{s h}}\left(x_{l_{f}, l_{f}-1}\right)+\left(\sum_{i^{\prime}} R_{i i^{\prime}}^{2}\right)_{\Delta n \neq 0} g_{s h}\left(x_{n_{i}, n_{i}+1}\right) \\
& -2 \sum_{i^{\prime}\left(\Delta E_{i^{\prime}}<0\right)} \sum_{L_{i^{\prime}} f_{i^{\prime}}} R_{l_{i}, l_{i^{\prime}}}^{2} g_{s h}\left(x_{l_{i}, l_{i^{\prime}}}\right)-\left(\sum_{f^{\prime}} R_{f f^{\prime}}^{2}\right) g_{\Delta n \neq 0} g_{s h}\left(x_{n_{f}, n_{f}+1}\right) \\
& \left.+2 \sum_{f,\left(\Delta E_{f^{\prime}, f}<0\right)} \sum_{L_{f}, J_{f},} R_{l_{f}, l_{f}}^{2}, g_{s h}\left(x_{l_{f}, l_{f}}\right)+\sum_{k} \delta_{k}\right],
\end{aligned}
$$

where the initial atomic energy level of the transition is denoted with $i$, final with $f, k$ is the Boltzmann constant, $c$ speed of light, $m$ mass of electron, $\hbar$ reduced Planck constant, $n$ principal, $l$ orbital and $L$ total orbital quantum numbers, while $j$ and $J$ are quantum numbers of angular and total angular momentum. The sum of squares of coordinate vector matrix elements $R_{k k^{\prime}}(k=i, j)$ for $\Delta n \neq 0$ in the Coulomb approximation is:

$$
\left(\sum_{k \prime} R_{k k^{\prime}}^{2}\right)_{\Delta n \neq 0}\left(\frac{3 n_{k}^{*}}{2 Z}\right)^{2} \frac{1}{9}\left(n_{k}^{* 2}+3 l_{k}^{2}+3 l_{k}+1\right)
$$

and

$$
x_{l_{k}, l_{k \prime}}=\frac{E}{\Delta E_{l_{k}, l_{k}}}, k=i, f,
$$

where $E=(3 / 2) k T$ is the kinetic energy of the colliding free electron, and $\Delta E_{l_{k}, l_{k}}=\left|E_{l_{k}}-E_{l_{k}}\right|$ is the energy difference between atomic energy levels with $l_{k}$ and $l_{k} \pm 1(k=i, f)$.

$$
x_{n_{k}, n_{k}+1} \approx \frac{E}{\Delta E_{n_{k}, n_{k}+1}}
$$

All perturbing atomic energy levels where $\Delta n \neq 0$ are lumped together and replaced with an average energy level [12]. The difference between the energies of initial or final energy level $\left(n_{k}, k=i, f\right)$ and this averaged level $\left(n_{k}+1\right)$ is approximated as [12]:

$$
\Delta E_{n_{k}, n_{k}+1} \approx \frac{2 Z^{2} E_{H}}{n_{k}^{* 3}}
$$


where

$$
n_{k}^{*}=\left[\frac{E_{H} Z^{2}}{\left(E_{\text {ion }}-E_{k}\right)}\right]^{1 / 2}
$$

is the effective principal quantum number, while the residual ionic charge $Z$ is 1 for atoms, 2 for singly charged ions, 3 for doubly charged ions, etc.; $E_{H}$ is ionization energy of hydrogen and $E_{i o n}$ of the considered spectral series; $N$ is electron density $T$ temperature; $g(x)$ [12] and $\tilde{g}(\mathrm{x})$ [7] are Gaunt factors for width and $g_{s h}(\mathrm{x})$ [12] and $\tilde{g}_{s h}(\mathrm{x})$ [9] for shift; $g(\mathrm{x})=0.2$ for $\mathrm{x} \leq 2$ and $g(\mathrm{x})=0.24,0.33,0.56,0.98,1.33$ for $\mathrm{x}=3,5,10,30$, and 100 [12]. $\tilde{g}(\mathrm{x})=0.7-1.1 / Z+g(\mathrm{x})$ [9]. For high temperature (or large $\mathrm{x}$ ) limit:

$$
\tilde{g_{j j \prime}}=g_{j j \prime}=\frac{\sqrt{3}}{\pi}\left[\frac{1}{2}+\ln \left(\frac{2 Z k T}{n_{j}^{* 2} \Delta E_{j j \prime}}\right)\right]
$$

For

$x=1,2,3,4,5,6,7,8,9,10,20,30,40,60,80,100$

$g_{s h}=0.20,0.25,0.32,0.41,0.45,0.51,0.56,0.60,0.63,0.66,0.78,0.82,0.84,0.85,0.86,0.87$

$\tilde{g}_{s h^{\prime}} \mathrm{Z}=20.350 .400 .470 .530 .580 .610 .640 .660 .680 .700 .780 .820 .840 .850 .860 .87$

$Z=30.530 .540 .570 .590 .620 .640 .660 .670 .690 .700 .780 .820 .840 .850 .860 .87$

$Z=40.620 .620 .630 .640 .650 .660 .670 .680 .690 .700 .780 .820 .840 .850 .860 .87$

$Z>40.88-1.1 / Z+0.01 x / Z 0.87$

The derivation of $\tilde{g}_{s h}(\mathrm{x})$ is described in detail in Reference [11]. In the equation for the shift:

$$
\sigma_{k k^{\prime}}=\left(E_{k^{\prime \prime}}-E_{k}\right) /\left|E_{k^{\prime}}-E_{k}\right|
$$

here, $E_{k}$ and $E_{k^{\prime}}$ are energies of the considered level and of its perturbing level, respectively.

If perturbing levels exist where the assumed approximations are strongly violated, i.e., if they are much closer to the considered level than the averaged perturbing level, this can be taken into account by adding for each such level in the equation for the shift:

$$
\delta_{i}= \pm R_{i i \prime}^{2}\left[g_{s h}\left(\frac{E}{\Delta E_{i i}}\right) \mp g_{s h}\left(x_{n_{i}, n_{i}+1}\right)\right]
$$

or

$$
\delta_{f}=\mp R_{f f \prime}^{2}\left[g_{s h}\left(\frac{E}{\Delta E_{f f}}\right) \mp g_{s h}\left(x_{n_{f}, n_{f}+1}\right)\right]
$$

where the lower sign corresponds to $\Delta E_{j^{\prime} j}<0$.

The advantage of the modified semiempirical method is that the set of atomic data needed for calculations is smaller than in the case of more sophisticated methods, for example the semiclassical perturbation one. Consequently, it is applicable particularly for complex atoms, where the reliable atomic data are not complete. It is also of interest when Stark broadening parameters are needed for a large number of spectral lines and an average accuracy is sufficient so that the big accuracy for each particular line is not critical.

\section{Applications of the Modified Semiempirical Method and Data Obtained by It}

\subsection{Astrophysics}

The Modified semiempirical method and data on Stark broadening of non-hydrogenic spectral lines, obtained by using this approach, were cited and used in astrophysics for different purposes. For the stars on main sequence, the influence of Stark broadening may be significant for stars of $A$ and B spectral type. 
For the research of B stars, the MSE method and the corresponding data were used, for example for non-LTE (Local Thermodynamical Equilibrium) calculations of silicon-line strengths [13] and determination of magnesium, aluminum, and silicon abundances in normal late-B stars from co-added IUE spectra [14] and nitrogen and oxygen abundances in early B-type stars [15].

In the case of A-type stars, the MSE method and data have been used, e.g., for determination of magnesium, aluminum, and silicon abundances in HgMn stars from co-added IUE spectra [14]. In stars of this type, the abundance of xenon has been determined [16] using the corresponding MSE Stark line widths [17], and MSE data for Pt II [18] have been used for an investigation of isotopic anomalies of platinum in the HgMn star HR-7775 [19]. MSE data for Stark broadening parameters of doubly and triply charged non-hydrogenic ion lines [20] have also been used for quantitative spectroscopy of hot stars [21].

Stark broadening is the most important pressure broadening mechanism, usually dominant in white dwarf atmospheres. Examples of the use of the MSE method and the corresponding data are investigation of equilibrium abundances of heavy elements supported by radiative levitation in the atmospheres of hot white dwarfs of type A (DA) [22] and radiative levitation in hot white dwarfs [23].

MSE theory and the corresponding Stark broadening data have been used as well for studies of radiative acceleration in stellar envelopes $[24,25]$ and investigations of radiative acceleration on carbon, nitrogen, oxygen [26], and iron $[27,28]$.

An interesting citation of the MSE data and method is in the article dealing with the calculation of thermodynamic and optical properties of the vapors of cosmic bodies, which enter into the Earth's atmosphere [29]. MSE data [17] for Stark broadening in plasma of spectral lines of ionized xenon were also used in a study with the aim of obtaining wavelengths and oscillator strengths for singly charged xenon from the UVES spectra of four HgMn stars [30].

A particularly important application of MSE theory and the corresponding data is for stellar [31-36] and solar [37] opacity calculations as well as for investigations and determination of opacity of different plasmas [38-47]. Accordingly, the MSE method and data have been used to determine opacities for classical Cepheid models [31], to calculate Rosseland mean opacities [36] and produce radiative atomic Rosseland mean opacity tables [33], for calculations of the radiative opacity of laser-produced [38,39] and hot and solid-dense [43] aluminum plasmas, for investigations of radiative opacities and configuration of interaction effects of hot Fe plasma [40], diagnostics for hot Br plasma by the open M-shell opacity [41], radiative opacity of plasmas studied by detailed term (level) accounting approaches [43], tin plasmas in the extreme-ultraviolet region [44], and dense C plasmas based on the detailed fine-structure level accounting formalism [45].

The corresponding formulae for Stark width of spectral lines are included in codes for radiative opacity calculations like OPAL [32] and DAVROS [46] and in RAPCAL code, a flexible package to compute radiative properties for optically thin and thick low- and high-Z plasmas across a wide range of density and temperature [47].

\subsection{Regularities and Systematic Trends}

Stark broadening data obtained by the MSE method [10,20,48-50], especially those in the STARK-B database, are widely used for investigations of regularities and systematic trends for Stark broadening parameters [51-77].

Dependences of Stark widths on the upper level ionization potential have been investigated for $\mathrm{N}$ I-N V [51,68], O I-O VI [53,68], Ne I-Ne VI [65,68], Ar III, Ar IV [65], Cl II, Cl III, Cl IV, F I-F IV [66,69], Kr I-Kr IV, Xe I, Xe II, Xe III [67], Si I-Si IV [68,69], and C IV [69] spectral lines, within different spectral series of neutral beryllium [60], lithium [62,64], and sodium [63,64] isoelectronic sequences. These data were used for the consideration of general regularities of Stark broadening parameters for ion lines [70], Stark parameter regularities of multiply charged ion spectral lines originating from the same transition array [73], and for checking the dependence on the upper level ionization potential of electron impact widths using quantum calculations [75]. 
The mentioned MSE Stark broadening data have been used for the investigation of regularities and systematic trends in isoelectronic sequences. Besides the already mentioned dependence on the ionization potential of the upper energy level of transition, MSE data were used for the investigation of the dependence on the emitter charge for the Stark broadening of lithium [52,54], boron [56], beryllium [57], and carbon [58] isoelectronic sequences.

Another topic is the investigation of regularities and systematic trends of Stark broadening parameters for spectral lines of non-hydrogenic homologous ions. Stark halfwidth trends along the homologous sequence of singly [74] and doubly ionized noble gases [61] have been investigated.

Additionally, the MSE approach and the corresponding Stark broadening data have been used in articles dealing with regularities in experimental Stark shifts [55], the effect of line-broadening on the overall width of transition arrays in dense plasmas [59], Stark broadening parameter prediction and regularities in the spectra of $\mathrm{Pb}$ II [71] and Sn II [72], core polarization effect for the Stark broadening of spectral lines of doubly charged lead, and predictions and regularities [77] and irregularities of Stark parameters of Xe II spectral lines [76].

\subsection{Lasers and Laser Produced Plasma}

An important topic for the application of the MSE method and data is laser produced plasma and lasers, where data from [10,20,78-86] and in particular [87] on Stark broadening of spectral lines of ionized copper have been used for various purposes. We took as examples References [88-121].

Here we present the most interesting cases in which MSE data have been used for investigation of laser produced plasmas. They were used for spectroscopic diagnostics of laser-induced plasmas [90], ultrafast laser produced zinc plasma investigation [91], and an experiment for verification of a radiative model of plasma induced by a laser that expands into a vacuum [95]. Of particular interest were data on Stark broadening of $\mathrm{Cu}$ II lines [87]. They were used in articles considering dependence of laser fluence on dynamics of emission of copper plasma induced by ultrafast laser [109], the effect of uniform magnetic field on it and the particles deposited on the surface of target [110], studies of time-integrated optical emission for Cu plasma in air at atmospheric pressure with magnetic field [112], radiation decay constant dependence on focal position for copper plasma [116], the effect of hyperfine structure on Stark broadening in the case of three blue-green $\mathrm{Cu}$ spectral lines in plasma induced by laser [118], enhancement of signal intensity using cavity confinement of plasma produced by a laser [114], the study of temporal evolution of plasma induced by $\mathrm{CO}_{2}$ pulsed laser on targets made of titanium oxides [99], the mechanism of effect of distance between a lens and a sample on plasma induced by laser [100], and the effect of ambient pressure on titanium plasma induced by a femtosecond laser [101].

Laser ablation is the process of irradiation of a solid surface with a laser beam in order to remove material from it. At high laser flux, the evaporated material is typically converted to a plasma, in which case MSE Stark broadening data also might be useful. Examples where such data are used are papers dealing with diagnostics and comparison of cadmium [96] and zinc plasma produced by laser ablation [103], diagnosis of plasma and nanostructure of deposits during laser ablation and deposition in the case of wide bandgap semiconductors [104], plume plasma characteristics and their influence on ablation depth during ultrashort laser ablation of $\mathrm{Cu}$ in air [105], melt ejection from $\mathrm{Cu}$ target by nanosecond pulsed laser ablation in air and with a magnetic field present [111], the quantitative elemental analysis of a silver alloy using laser-ablation spark-induced breakdown spectroscopy [119], and laser-plasma interaction and plasma enhancement using ultrashort double-pulse ablation [108].

Another research field where MSE Stark broadening data are needed is laser-induced breakdown spectroscopy (LIBS), a type of atomic emission spectroscopy where a highly energetic laser pulse is focused to form a plasma, which atomizes and excites samples. Examples of articles where MSE Stark broadening data have been used and cited are on LIBS using mid-infrared femtosecond pulses [107], fiber-optic LIBS of zirconium metal in air [97], investigation of self-absorption of Mn emission lines in LIBS measurements [98], optimization of the temporal window for employment of calibration 
free-LIBS on Cu alloys in air using a single line study [117], investigation of the matrix effect on the plasma characterization of heavy elements in soil sediments with LIBS and a portable echelle spectrometer [102], femtosecond double pulse LIBS-investigation of intensity enhancement [113], calibration-free analysis of immersed metal alloys with long-pulse-duration LIBS [115], and influence of correction for self-absorption on LIBS measurements using a calibration curve and an artificial neural network [120].

Additionally, the considered MSE data have been used for laser design and development, e.g., for XUV (high-energy X ultraviolet radiation) lasers driven by femtosecond pulse and excited by electrons in noble gases charged eight times [92] and at $41.8 \mathrm{~nm}$ in Xe IX [93,94], designs for a compact Ni-like-wolfram X-ray laser [89], as well as for consideration of photoresonant X-ray laser pumping [88], for the study of spectra of plasma in selective laser micro sintering copper-based metal powder [106], and for experimental investigation of near-resonance-Rayleigh scattering on Ba plasma driven by a laser [121].

\subsection{Radiative Properties}

MSE Stark broadening data from $[10,49,78,82,122,123]$ have been used in papers with the aim of determining transition probabilities in the spectra of C III [124]; N III, N IV, and N V [125]; V III [126]; Co III [127]; Cd I [128]; Cd II [128,129]; Zn II [130,131]; Au II [132,133]; Eu II and Eu III [134]; and Si IV and Ti IV [131]. Oscillator strengths have also been determined for Eu II and Eu III [134], Zn II [130,131,135], and Si IV and Ti IV [131] as well as radiative lifetimes for Cd I and Cd II [128], Au II [132], Eu II and Eu III [134], Zn II [130,131,135,136], and Si IV and Ti IV [131].

The considered data have been useful for articles with radiative emission and absorption as the subject. Examples of such papers consider a line-by-line approach of determining emission coefficients for thermal plasmas consisting of monoatomic species [137]; theoretically obtained results for radiative emission for argon and copper thermal plasmas [138]; net emission coefficients for Ar-Fe thermal plasmas [139,140]; complex thermal plasmas, which are used in single-wall carbon nanotube synthesis [141]; net emission coefficients at atmospheric pressure for argon-aluminum, argon-iron, and argon-copper mixtures in welding processes using plasmas [142]; research of the L-shell absorption of open-M-shell Ge plasmas and its effect of autoionization resonance broadening [143]; and autoionization widths of open-M-shell Ge ions and their influence on inner-shell absorption [144].

There are also papers on photoabsorption in Zn II [145], Zn III [146], Ga III, Ge IV [145] and Ge $\mathrm{V}$ [146] using MSE data as well as on photoionization of $\mathrm{Fe}^{7+}, \mathrm{Fe}^{8+}$ [147], and O III [148]; nuclear excitation by electron transition rate confidence interval in ${ }^{201} \mathrm{Hg}$ local thermodynamic equilibrium plasma [149]; electron-impact excitation of the $\left(5 \mathrm{~d}^{10} 6 \mathrm{~s}\right)^{2} \mathrm{~S}_{1 / 2}-\left(5 \mathrm{~d}^{10} 6 \mathrm{p}\right)^{2} \mathrm{P}_{1 / 2,3 / 2}^{\mathrm{o}}$ resonance transitions in gold atoms [150]; chemi-ionization processes in slow collisions of Rydberg atoms with ground state atoms [151]; and XUV amplification considering recombination in clusters [152].

\subsection{Plasma Diagnostics}

Stark broadening data are also useful for spectroscopic diagnostics of various plasmas. For these purposes MSE data have been used, for example, for spectroscopic diagnostics of railgun plasma armatures [153], electron density diagnostics [154-157], spectroscopic consideration of plasma during electrolytic oxidation of aluminum [158], and MSE data from [87] have been used for investigation of plasma near the implosion of a shockwave created by an underwater electrical explosion of a spherical wire array [159].

\subsection{Other Applications of MSE Data}

Finally, MSE data have been useful for investigations like initiation of a formation of an arc at a plasma-wall contact [160] and quick creation of approximate spectra of dense cool plasmas in the optical wavelength range [161]. Data from [87] have been used in papers dealing with propagation distance-resolved characteristics of filament-induced $\mathrm{Cu}$ plasma [162], heterogeneous 
(Cu-Ti) colliding plasma dynamic [163] and initiation process of vacuum breakdown between copper $\mathrm{u}$ and copper-chrome electrodes [164]. Data from [17] have been used in a paper dealing with the zone of compression of a magnetoplasma compressor as a source of extreme ultraviolet radiation [165]. Data from [123] have been used for an atomic spectral line free parameter deconvolution procedure [166], and data from [167] have been used for the determination of expectation values of the neutral chromium radius [168].

\section{Conclusions}

From the analysis of applications of the modified semiempirical method [9-11] and of Stark broadening data calculated using this approach, it can be seen that the main applications of these data are in astronomy, investigations of laser produced plasmas, laser design and optimization and their applications in industry and technology, as well as in the determination of radiative properties of various plasmas and the corresponding research.

In astronomy, the main applications are the investigation of stars of A and B spectral type and white dwarfs. We note that in the case of atmospheres of white dwarfs, Stark broadening dominates the thermal Doppler broadening, and for problems like modeling of atmospheres, analysis and synthesis of stellar spectra, abundance determinations, different calculations of radiative transfer, and studies of radiative acceleration in stellar envelopes diagnostics of white dwarf plasma, Stark broadening data are essential. For stars of A type, the principal pressure broadening mechanism is Stark broadening, the neglecting of which may introduce errors, for example in abundance determinations. For stars of $B$ type, Stark broadening data are needed, since this broadening mechanism may be non-negligible for some lines. Another very important astronomical application is for opacity calculations, so that the corresponding codes like OPAL include the modified semiempirical formula for calculation of Stark broadening data.

Investigation of laser produced plasma, lasers, and their use in industry is also a research field where MSE data are widely used. These data are particularly useful for modeling and diagnostics of laser produced plasma, laser ablation, deposition and melting, laser-plasma interaction, laser-induced breakdown spectroscopy, and for laser design and development.

Concerning determination and investigation of radiative properties of various plasmas, MSE Stark broadening data may be useful for investigations of oscillator strengths, transition probabilities, radiative lifetimes, emission coefficients, photoabsorption, and photoionization.

MSE Stark broadening data are also widely used for plasma diagnostics and for investigations of regularities and systematic trends of such quantities.

We performed a similar analysis [169] of Stark broadening data for non-hydrogenic atoms and ions obtained by using the semiclassical perturbation method (SCP) [4,5]. If we compare the conclusions for SCP data, obtained by a more sophisticated method that needs more atomic data and more complex calculations, and for MSE Stark broadening data, we can see that SCP data are much more frequently used in astronomy, while MSE data are more common for calculations where such data for a lot of lines are needed and an average accuracy is more important than a high accuracy of data for each particular spectral line. MSE data are more often used when a high degree of precision is not required, such as for laser produced plasma, especially in technology and industry. Additionally, users of SCP data, due to the difficulty of calculation, use only data, while users of MSE data, which are simpler to calculate, use not only data but include the corresponding MSE formulas in their computer codes or calculate data for spectral lines that do not exist in the literature.

MSE data discussed here, as with SCP data, are continuously implemented in the STARK-B database $[6-8,170,171]$ and are available online. STARK-B is also a part of the Virtual Atomic and Molecular Data Center (VAMDC) [172,173] and may be accessed through its portal [174].

Funding: This research received no external funding.

Conflicts of Interest: The author declares no conflict of interest. 


\section{References}

1. Griem, H.R. Spectral Line Broadening by Plasmas; Academic Press: New York, NY, USA; London, UK, 1974.

2. Oks, E. Diagnostics of Laboratory and Astrophysical Plasmas Using Spectral Lineshapes of One-, Two-, and Three-Electron Systems; World Scientific: Singapore, 2017.

3. Elabidi, H.; Sahal-Bréchot, S.; Dimitrijević, M.S.; Ben Nessib, N. Quantum Stark broadening data for the C IV, N V, O VI, F VII and Ne VIII resonance doublets. MNRAS 2011, 417, 2624-2630. [CrossRef]

4. Sahal-Bréchot, S. Impact theory of the broadening and shift of spectral lines due to electrons and ions in a plasma (continued). Astron. Astrophys. 1969, 2, 322-354.

5. Sahal-Bréchot, S. Impact theory of the broadening and shift of spectral lines due to electrons and ions in a plasma. Astron. Astrophys. 1969, 1, 91-123.

6. Sahal-Bréchot, S.; Dimitrijević, M.S.; Moreau, N.; Ben Nessib, N. The STARK-B Database as a Resource for "STARK" Widths and Shifts Data: State of Advancement and Program of Development. Adv. Space Res. 2014, 54, 1148-1151. [CrossRef]

7. Sahal-Bréchot, S.; Dimitrijević, M.S.; Moreau, N.; Ben Nessib, N. The STARK-B Database VAMDC node: A Repository for Spectral Line Broadening and Shifts Due to Collisions with Charged Particles. Phys. Scr. 2015, 50, 054008. [CrossRef]

8. STARK-B. Available online: http://stark-b.obspm.fr (accessed on 12 July 2020).

9. Dimitrijević, M.S.; Konjević, N. Stark widths of doubly- and triply-ionized atom lines. J. Quant. Spectrosc. Radiat. Transf. 1980, 24, 451-459. [CrossRef]

10. Dimitrijević, M.S.; Konjević, N. Modified semiempirical formula for the electron impact width of ionized atom lines: Theory and applications. In Spestral Line Shapes; Wende, B., Ed.; Walter de Gruyter: Berlin, Germany; New York, NY, USA, 1981; pp. 211-239.

11. Dimitrijević, M.S.; Kršljanin, V. Electron-impact shifts of ion lines-Modified semiempirical approach. Astron. Astrophys. 1986, 165, 269-274.

12. Griem, H.R. Semiempirical Formulas for the Electron-Impact Widths and Shifts of Isolated Ion Lines in Plasmas. Phys. Rev. 1968, 165, 258-266. [CrossRef]

13. Lennon, D.J.; Lynas-Gray, A.E.; Brown, P.J.F.; Dufton, P.L. Non-LTE calculations of silicon-line strengths in B-type stars. Mon. Not. Roy. Astron. Soc. 1986, 222, 719-729. [CrossRef]

14. Smith, K.C. Elemental abundances in normal late-B and HgMn stars from co-added IUE spectra. 2. Magnesium, aluminium and silicon. Astron. Astrophys. 1993, 276, 393-408.

15. Gies, D.R.; Lambert, D.L. Carbon, Nitrogen and Oxygen abundances in early B-type stars. Astrophys. J. 1992, 387, 673-700. [CrossRef]

16. Dworetsky, M.M.; Persaud, J.L.; Patel, K. Xenon in mercury-manganese stars. Mon. Not. R. Astron. Soc. 2008, 385, 1523-1529. [CrossRef]

17. Popović, L.Č.; Dimitrijević, M.S. Stark broadening of Xe II lines. Astron. Astrophys. Suppl. Ser. 1996, 116, 359-365. [CrossRef]

18. Dimitrijević, M.S. Stark broadening of Pt II lines in chemically peculiar stars. Astrophys. Lett. Commun. 1993, 28, 381-383.

19. Bohlender, D.A.; Dworetsky, M.M.; Jomaron, C.M. Isotopic anomalies of platinum in the mercury manganese star HR-7775. Astrophys. J. 1998, 504, 533-538. [CrossRef]

20. Dimitrijević, M.S. Electron-impact widths of doubly and triply charged ion lines of astrophysical importance. Astron. Astrophys. Suppl. Ser. 1988, 76, 53-59.

21. Kudritzki, R.; Hummer, D.G. Quantitative spectroscopy of hot stars. Ann. Rev. Astron. Astrophys. 1990, 28, 303-345. [CrossRef]

22. Chayer, P.; Vennes, S.; Pradhan, A.K.; Thejll, P.; Beauchamp, A.; Fontaine, G.; Wesemael, F. Improved calculations of the equilibrium abundances of heavy elements supported by radiative levitation in the atmospheres of hot DA white dwarfs. Astrophys. J. 1995, 454, 429-441. [CrossRef]

23. Chayer, P.; Fontaine, G.; Wesemael, F. Radiative levitation in hot white dwarfs: Equilibrium theory. Astrophys. J. Suppl. Ser. 1995, 99, 189-221. [CrossRef]

24. Seaton, M.J. Radiative Accelerations in Stellar Envelopes. MNRAS 1997, 289, 700-720. [CrossRef]

25. Gonzales, J.F.; LeBlanc, F.; Artru, M.-C.; Michaud, G. Improvements on radiative acceleration calculations in stellar envelopes. Astron. Astrophys. 1995, 297, 223-236. 
26. Gonzales, J.F.; Artru, M.-C.; Michaud, G. Radiative accelerations on carbon, nitrogen and oxygen. Astron. Astrophys. 1995, 302, 788-796.

27. LeBlanc, F.; Michaud, G. Radiative accelerations on iron. Astron. Astrophys. 1995, 303, 166-174.

28. Alecian, G.; Michaud, G.; Tully, J. Radiative Accelerations on Iron Using Opacity Project Data. Astrophys. J. 1993, 411, 882-890. [CrossRef]

29. Kosarev, I.B. Calculation of thermodynamic and optical properties of the vapors of cosmic bodies entering the Earth's atmosphere. J. Eng. Phys. Thermodyn. 1999, 72, 1030-1038. [CrossRef]

30. Yüce, K.; Castelli, F.; Hubrig, S. Wavelengths and oscillator strengths of Xe II from the UVES spectra of four HgMn stars. Astron. Astrophys. 2011, 528, A37. [CrossRef]

31. Iglesias, C.A.; Rogers, F.J.; Wilson, B.G. Opacities for classical cepheid models. Astrophys. J. 1990, 360, $221-226$. [CrossRef]

32. Iglesias, C.A.; Rogers, F.J. Results obtained using the OPAL code. Rev. Mex. Astron. Astrofis. 1992, 23, 161-170.

33. Rogers, F.J.; Iglesias, C.A. Radiative atomic Rosseland mean opacity tables. Astrophys. J. Suppl. Ser. 1992, 79, 507-568. [CrossRef]

34. Mostovych, A.N.; Chan, L.Y.; Kearney, K.J.; Garren, D.; Iglesias, C.A.; Klapisch, M.; Rogers, F.J. Opacity of dense, cold, and, strongly coupled plasmas. Phys. Rev. Lett. 1995, 75, 1530-1533. [CrossRef]

35. Rogers, F.J.; Iglesias, C.A. Opacity of stellar matter. Space Sci. Rev. 1999, 85, 61-70. [CrossRef]

36. Seaton, M.J.; Badnell, N.R. A comparison of Rosseland-mean opacities from OP and OPAL. MNRAS 2004, 354, 457-465. [CrossRef]

37. Krief, M.; Feigel, A.; Gazit, D. Solar Opacity Calculations Using the Super-transition-array Method. Astrophys. J. 2016, 821, 45. [CrossRef]

38. Zeng, J.; Yuan, J.; Lu, Q. Detailed-term-accouting-approximation calculations of the radiative opacity of laser-produced Al plasmas. Phys. Rev. E 2001, 64, 066412. [CrossRef]

39. Zeng, J.; Yuan, J. Detailed-term-accouting-approximation calculations of the radiative opacity of aluminium plasmas: A systematic study. Phys. Rev. E 2002, 66, 06401. [CrossRef]

40. Jin, F.; Zeng, J.; Yuan, J. Radiative opacities and configuration interaction effects of hot iron plasma using a detailed term accounting model. Phys. Rev. E 2003, 68, 066401. [CrossRef]

41. Jin, F.; Yuan, J. Detailed diagnostics for a hot bromine plasma by the open M-shell opacity. Phys. Rev. E 2005, 72, 016404. [CrossRef]

42. Zeng, J.L.; Jin, F.T.; Yuan, J.M. Radiative opacity of plasmas studied by detailed term (level) accounting approaches. Front. Phys. 2006, 4, 468-489. [CrossRef]

43. Li, Y.; Wu, J.; Hou, Y.; Yuan, J. Radiative opacities of hot and solid-dense aluminium plasmas using a detailed level accounting model. J. Phys. B 2009, 42, 235701. [CrossRef]

44. Zeng, J.; Gao, C.; Yuan, J. Detailed investigations on radiative opacity and emissivity of tin plasmas in the extreme-ultraviolet region. Phys. Rev. E 2010, 82, 026409. [CrossRef]

45. Gao, C.; Zeng, J.; Yuan, J. Plasma screening effects on the atomic structure and radiative opacity of dense carbon plasmas based on the DLA model. High Energy Density Phys. 2011, 7, 54-60. [CrossRef]

46. Upcraft, L.M.; Jeffery, M.; Harris, J.W.O. The DAVROS opacity code: Detailed term accounting calculations for LTE plasmas. High Energy Density Phys. 2015, 14, 59-66. [CrossRef]

47. Rodriguez, R.; Florido, R.; Gil, J.M.; Rubiano, J.G.; Martel, P.; Minguez, E. RAPCAL code: A flexible package to compute radiative properties for optically thin and thick low and high-Z plasmas in a wide range of density and temperature. Laser Part. Beams 2008, 26, 433-448. [CrossRef]

48. Popović, L.Č.; Dimitrijević, M.S. Stark broadening of heavy ion lines: As II, Br II, Sb II and I II. Phys. Scr. 1996, 53, 325-331. [CrossRef]

49. Popović, L.Č.; Dimitrijević, M.S.; Ryabchikova, T. The electron-impact broadening effect in CP stars: The case of La II, La III, Eu II, and Eu III lines. Astron. Astrophys. 1999, 350, 719-724.

50. Dimitrijević, M.S.; Tankosić, D. On the variation of Stark line shifts within a given spectrum in the case of irregular energy level structure. Phys. Scr. 2000, 62, 177-182. [CrossRef]

51. Purić, J.; Srećković, A.; Djeniže, S.; Platiša, M. Stark broadening and regularities of prominent multiply ionized nitrogen spectral lines. Phys. Rev. A 1987, 36, 3957-3963. [CrossRef]

52. Bottcher, F.; Breger, P.; Hey, J.D.; Kunze, H.J. Dependence of the Stark broadening on the emitter charge for the 3s-3p transitions of Li-like ions. Phys. Rev. A 1988, 38, 2690-2693. [CrossRef] 
53. Purić, J.; Djeniže, S.; Srećković, A.; Platiša, M.; Labat, J. Stark-broadening regularities of prominent multiply-ionized-oxygen spectral lines in plasma. Phys. Rev. A 1988, 37, 498-503. [CrossRef]

54. Glenzer, S.; Uzelac, N.I.; Kunze, H.-J. Stark-broadening of spectral-lines along the isoelectronic sequence of Li. Phys. Rev. A 1992, 45, 8795-8802. [CrossRef]

55. Wiese, W.L.; Konjević, N. Regularities in experimental Stark shifts. JQSRT 1992, 47, 185-200. [CrossRef]

56. Glenzer, S.; Hey, J.D.; Kunze, H.J. Stark broadening of spectral lines along the isoelectronic sequence of B. J. Phys. B 1994, 27, 413-422. [CrossRef]

57. Wrubel, T.; Ahmad, I.; Buscher, S.; Kunze, H.J. Stark-Broadening along the Berylliumlike Sequence. Phys. Rev. E 1998, 57, 5972-5977. [CrossRef]

58. Ivković, M.; Ben Nessib, N.; Konjević, N. Stark broadening of $3 \mathrm{~s}^{3} \mathrm{P}^{\mathrm{o}}-3 \mathrm{p}{ }^{3} \mathrm{D}$ and $3 \mathrm{p}^{3} \mathrm{D}-3 \mathrm{~d}^{3} \mathrm{~F}^{\mathrm{o}}$ transitions along carbon isoelectronic sequences of ions revisited. J. Phys. B 2005, 38, 715-728. [CrossRef]

59. Hoarty, D.J.; Bentley, C.D.; Crowley, B.J.B.; Davidson, S.J.; Gales, S.G.; Graham, P.; Harris, J.W.O.; Iglesias, C.A.; James, S.F.; Smith, C.C. The effect of line-broadening on the overall width of transition arrays in dense plasmas. J. Quant. Spectrosc. Radiat. Transf. 2006, 99, 283-294. [CrossRef]

60. Dojčinović, I.P.; Tapalaga, I.; Purić, J. Stark Width Regularities within Beryllium Spectral Series. Publ. Astron. Soc. Aust. 2011, 28, 281-289. [CrossRef]

61. Pelaez, R.J.; Djurović, S.; Ćirišan, M.; Aparicio, J.A.; Mar, S. Stark halfwidth trends along the homologous sequence of doubly ionized noble gases. Astron. Astrophys. 2012, 539, A40. [CrossRef]

62. Tapalaga, I.; Trklja, N.; Dojčinović, I.P.; Purić, J. Stark width regularities within spectral series of the lithium isoelectronic sequence. MNRAS 2018, 474, 5479-5484. [CrossRef]

63. Trklja, N.; Tapalaga, I.; Dojčinović, I.P.; Purić, J. Stark widths regularities within spectral series of sodium isoelectronic sequence. New Astron. 2018, 59, 54-59. [CrossRef]

64. Purić, J.; Djeniže, S.; Labat, J.; Platiša, M.; Srećković, A.; Ćuk, M. Stark-broadening regularities of lithium-like and sodium-like isoelectronic sequences. Z. Phys. D 1988, 10, 431-436. [CrossRef]

65. Purić, J.; Djeniže, S.; Srećković, A.; Ćuk, M.; Labat, J.; Platiša, M. Stark broadening and regularities of ionized neon and argon spectral lines. Z. Phys. D 1988, 8, 343-347. [CrossRef]

66. Purić, J.; Srećković, A.; Djeniže, S.; Platiša, M. Stark broadening and regularities of prominent spectral lines of multiply ionized chlorine and fluorine. Phys. Rev. A 1988, 37, 4380-4386. [CrossRef] [PubMed]

67. Purić, J.; Djeniže, S.; Labat, J.; Srećković, A.; Platiša, M. Stark broadening regularities within successive ionization stages in krypton and xenon. Contrib. Plasma Phys. 1991, 31, 63-69. [CrossRef]

68. Djeniže, S.; Labat, J.; Platiša, M.; Srećković, A.; Purić, J. Stark-broadening regularities of np-nd transition arrays of nitrogen, oxygen, neon, and silicon ion spectral lines. Astron. Astrophys. 1990, 227, 291-293.

69. Purić, J.; Miller, M.H.; Lesage, A. Electron impact broadening parameters predictions from regularities: Fe I, Fe II, Fe III, Fe IV, C IV and Si IV. Astrophys. J. 1993, 416, 825-830. [CrossRef]

70. Purić, J.; Šćepanović, M. General Regularities of Stark Parameters for Ion Lines. Astrophys. J. 1999, 521, 490-491. [CrossRef]

71. Colon, C.; Alonso-Medina, A. Stark broadening parameters prediction and regularities of singly ionized lead. J. Phys. B 2002, 35, 1143-1153.

72. Colon, C.; Alonso-Medina, A.; Rivero, C.; Fernandez, F. Stark width and shift parameter predictions and regularities of Sn II. Phys. Scr. 2006, 73, 410-419. [CrossRef]

73. Purić, J.; Dojčinović, I.P.; Nikolić, M.; Šćepanović, M.; Obradović, B.M.; Kuraica, M.M. Stark parameter regularities of multiply charged ion spectral lines originating from the same transition array. Astrophys. J. 2008, 680, 803-808. [CrossRef]

74. Peláez, R.J.; Djurović, S.; Ćirišan, M.; Aparicio, J.A.; Mar, S. Stark halfwidth trends along the homologous sequence of singly ionized noble gases. Astron. Astrophys. 2010, 518, A60. [CrossRef]

75. Elabidi, H.; S.Sahal-Bréchot, S. Checking the dependence on the upper level ionization potential of electron impact widths using quantum calculations. Eur. Phys. J. D 2011, 61, 285-290. [CrossRef]

76. Peláez, R.J.; Djurović, S.; Ćirišan, M.; Aparicio, J.A.; Mar, S. Irregularities of Stark parameters of Xe II spectral lines. J. Phys. B 2009, 42, 125002. [CrossRef]

77. Zanon, A.; Alonso-Medina, A.; Colon, C. Core polarization effect for the Stark broadening of Pb III spectral lines predictions and regularities. Int. Rev. At. Mol. Phys. 2010, 1, 1-11.

78. Popović, L.Č.; Vince, I.; Dimitrijević, M.S. Stark broadening of Zn II and Cd II spectral lines of astrophysical interest. Astron. Astrophys. Suppl. Ser. 1993, 102, 17-23. 
79. Popović, L.Č.; Dimitrijević, M.S. Stark broadening parameter tables for Xe II, Sc II, Y II and Zr II. Bull. Astron. Belgrade 1997, 155, 159-164.

80. Popović, L.Č.; Dimitrijević, M.S. The electron impact broadening parameters in hot star atmospheres: Mn II, Mn III, Ga III, Ge III and Ge IV lines. Astron. Astrophys. Suppl. Ser. 1998, 128, 203-205. [CrossRef]

81. Tankosić, D.; Popović, L.Č.; Dimitrijević, M.S. Electron-impact Stark broadening parameters for Ti II and Ti III spectral lines. At. Data Nucl. Data Tables 2001, 77, 277-310. [CrossRef]

82. Tankosić, D.; Popović, L.Č.; Dimitrijević, M.S. The electron-impact broadening parameters for Co III spectral lines. Astron. Astrophys. 2003, 399, 795-797. [CrossRef]

83. Simić, Z.; Dimitrijević, M.S.; Milovanović, N.; Sahal-Bréchot, S. Stark broadening of Cd I spectral lines. Astron. Astrophys. 2005, 441, 391-393. [CrossRef]

84. Popović, L.Č.; Dimitrijević, M.S. Tables of the electron impact broadening parameters: Mn II, Mn III, Ga III, Ge III and Ge IV lines. Bull. Astron. Belgrade 1997, 156, 173-178.

85. Simić, Z.; Dimitrijević, M.S.; Popović, L.Č.; Dačić, M.D. Stark broadening parameters for Cu III, Zn III and Se III lines in laboratory and stellar plasma. New Astron. 2006, 12, 187-191. [CrossRef]

86. Dimitrijević, M.S.; Konjević, N. Semiempirical Stark linewidths of alkali like ions. Astron. Astrophys. 1981, 102, 93-96.

87. Zmerli, B.; Ben Nessib, N.; Dimitrijević, M.S.; Sahal-Bréchot, S. Stark broadening calculations of neutral copper spectral lines and temperature dependence. Phys. Scr. 2010, 82, 055301. [CrossRef]

88. Fill, E.E.; Schoning, T. Linewidth Calculations of Si11 ${ }^{+}$and $\mathrm{Mg} 9^{+}$Resonance Lines and Applications to Photoresonant X-ray Laser Pumping. J. Appl. Phys. 1994, 76, 1423-1430. [CrossRef]

89. Decker, C.D.; London, R.A. Designs for a Compact Ni-Like-Tungsten X-ray Laser. Phys. Rev. A 1998, 57, 1395-1399. [CrossRef]

90. Konjević, N.; Ivković, M.; Jovićević, S. Spectroscopic diagnostics of laser-induced plasmas. Spectrochim. Acta B 2010, 65, 593-602. [CrossRef]

91. Rao, K.H.; Smijesh, N.; Nivas, J.J.; Philip, R. Ultrafast laser produced zinc plasma: Stark broadening of emission lines in nitrogen ambient. Phys. Plasmas 2016, 23, 043503. [CrossRef]

92. Lemoff, B.E.; Barty, C.P.J.; Harris, S.E. Femtosecond-pulse-driven, electron-excited XUV lasers in eight-times-ionized noble gases. Opt. Lett. 1994, 19, 569-571. [CrossRef]

93. Lemoff, B.E.; Yinm, G.Y.; Gordon, C.L.; Barty, C.P.J.; Harris, S.E. Demonstration of a 10-Hz femtosecond-pulse-driven XUV laser at $41.8 \mathrm{~nm}$ in Xe IX. Phys. Rev. Lett. 1995, 74, 1574-1577. [CrossRef]

94. Lemoff, B.E.; Yin, G.Y.; Gordon, C.L.; Barty, C.P.J.; Harris, S.E. Femtosecond-Pulse-Driven 10-Hz 41.8-nm Laser in Xe-IX. J. Opt. Soc. Am. B Opt. Phys. 1996, 13, 180-184. [CrossRef]

95. Gornushkin, I.B.; Kazakov, A.Y.; Omenetto, N.; Smith, B.W.; Winefordner, J.D. Experimental verification of a radiative model of laser-induced plasma expanding into vacuum. Spectrochim. Acta B 2005, 60, 215-230. [CrossRef]

96. Shaikh, N.M.; Rashid, B.; Hafeez, S.; Mahmood, S.; Saleem, M.; Baig, M.A. Diagnostics of cadmium plasma produced by laser ablation. J. Appl. Phys. 2006, 100, 073102. [CrossRef]

97. Matsumoto, A.; Ohba, H.; Toshimitsu, M.; Akaoka, K.; Ruas, A.; Sakka, T.; Wakaida, I. Fiber-optic laser-induced breakdown spectroscopy of zirconium metal in air: Special features of the plasma produced by a long-pulse laser. Spectrochim. Acta B 2018, 142, 37-49. [CrossRef]

98. Bredice, F.; Borges, F.O.; Sobral, H.; Villagran-Muniz, M.; Di Roco, H.O.; Cristoforetti, G.; Legnaioli, S.; Palleschi, V.; Pardini, L.; Salvetti, A.; et al. Evaluation of self-absorption of manganese emission lines in Laser Induced Breakdown Spectroscopy measurements. Spectrochim. Acta B 2006, 61, 1294. [CrossRef]

99. Diaz, L.; Camacho, J.J.; Sanz, M.; Hernández, M.; Jandova, V.; Castillejo, M. Temporal evolution study of the plasma induced by $\mathrm{CO}_{2}$ pulsed laser on targets of titanium oxides. Spectrochim. Acta B 2013, 86, 88-93. [CrossRef]

100. Liu, Y.H.; Chen, M.; Liu, X.D.; Cui, Q.Q.; Zhao, M.W. The mechanism of effect of lens-to-sample distance on laser-induced plasma. Acta Phys. Sin. 2013, 62, 025203.

101. Liu, D.; Chen, C.; Gao, X.; Lin, J.; Man, B.; Sun, Y.; Li, F. Effect of ambient pressure on a femtosecond laser induced titanium plasma. Eur. Phys. J. D 2016, 70, 245. [CrossRef]

102. Mohamed, W.T.Z.; Askar, A. Study of the Matrix Effect on the Plasma Characterization of Heavy Elements in Soil Sediments using LIBS with a Portable Echelle Spectrometer. Prog. Phys. 2007, 1, 46-52. 
103. Shaikh, N.M.; Hafeez, S.; Baig, M.A. Comparison of zinc and cadmium plasma produced by laser ablation. Spectrochim. Acta B 2007, 62, 1311-1320. [CrossRef]

104. Sanz, M.; Lopez-Arias, M.; Rebollar, E.; de Nalda, R.; Castillejo, M. Laser ablation and deposition of wide bandgap semiconductors: Plasma and nanostructure of deposits diagnosis. J. Nanopart. Res. 2012, 13, 6621-6631. [CrossRef]

105. Hu, W.; Shin, Y.C.; King, G. Characteristics of plume plasma and its effects on ablation depth during ultrashort laser ablation of copper in air. J. Phys. D Appl. Phys. 2012, 45, 355204. [CrossRef]

106. Cheng, D.; Zhu, H.; Ke, L. Investigation of plasma spectra during selective laser micro sintering Cu-based metal powder. Rapid Prototyp. J. 2013, 19, 373-382. [CrossRef]

107. Hartig, K.C.; Colgan, J.; Kilcrease, D.P.; Barefield, J.E.; Jovanovic, I. Laser-induced breakdown spectroscopy using mid-infrared femtosecond pulses. J. Appl. Phys. 2015, 118, 043107. [CrossRef]

108. Zhao, X.; Shin, Y.C. Laser-plasma interaction and plasma enhancement by ultrashort double-pulse ablation. Appl. Phys. B 2015, 120, 81-87. [CrossRef]

109. Anoop, K.K.; Harilal, S.S.; Philip, R.; Bruzzese, R.; Amoruso, S. Laser fluence dependence on emission dynamics of ultrafast laser induced copper plasma. J. Appl. Phys. 2016, 120, 185901. [CrossRef]

110. Singh, K.S.; Khare, A.; Sharma, A.K. Effect of uniform magnetic field on laser-produced Cu plasma and the deposited particles on the target surface. Laser Part. Beams 2017, 35, 352-361. [CrossRef]

111. Singh, K.S.; Sharma, A.K. Melt ejection from copper target in air in the presence of magnetic field using nanosecond pulsed laser ablation. J. Vac. Sci. Technol. A Vac. Surf. Film. 2017, 35, 031305. [CrossRef]

112. Singh, K.S.; Sharma, A.K. Time-integrated optical emission studies on laser-produced copper plasma in the presence of magnetic field in air ambient at atmospheric pressure. Appl. Phys. A 2017, 123, 325. [CrossRef]

113. Ahamer, C.M.; Pedarnig, J.D. Femtosecond double pulse laser-induced breakdown spectroscopy: Investigation of the intensity enhancement. Spectrochim. Acta Part B At. Spectrosc. 2018, 148, 23-30. [CrossRef]

114. Ahmed, R.; Akthar, M.; Jabbar, A.; Umar, Z.A.; Ahmed, N.; Iqbal, J.; Baig, M.A. Signal Intensity Enhancement by Cavity Confinement of Laser-Produced Plasma. IEEE Trans. Plasma Sci. 2019, 47, 1616-1620. [CrossRef]

115. Jabbar, A.; Hou, Z.; Liu, J.; Ahmed, R.; Mahmood, S.; Wang, Z. Calibration-free analysis of immersed metal alloys using long-pulse-duration laser-induced breakdown spectroscopy. Spectrochim. Acta Part B At. Spectrosc. 2019, 157, 84-90. [CrossRef]

116. Junjuri, R.; Rashkovskiy, S.A.; Gundawar, M.K. Dependence of radiation decay constant of laser produced copper plasma on focal position. Phys. Plasmas 2019, 26, 122107. [CrossRef]

117. Mal, E.; Junjuri, R.; Gundawar, M.K.; Khare, A. Optimization of temporal window for application of calibration free-laser induced breakdown spectroscopy (CF-LIBS) on copper alloys in air employing a single line. J. Anal. At. Spectrom. 2019, 34, 319-330. [CrossRef]

118. Popov, A.M.; Sushkov, N.I.; Zaytsev, S.M.; Labutin, T.A. The effect of hyperfine splitting on Stark broadening for three blue-green Cu I lines in laser-induced plasma. Mon. Not. R. Astron. Soc. 2019, 488, 5594-5603. [CrossRef]

119. Gao, J.; Kang, J.; Li, R.; Chen, Y. Application of calibration-free high repetition rate laser-ablation spark-induced breakdown spectroscopy for the quantitative elemental analysis of a silver alloy. Appl. Opt. 2020, 59, 4091-4096. [CrossRef]

120. Rezaei, F.; Karimi, P.; Tavassoli, S.H. Effect of self-absorption correction on LIBS measurements by calibration curve and artificial neural network. Appl. Phys. B 2013, 114, 591-600. [CrossRef]

121. Nee, T.-J.A. Near-resonance-Rayleigh scattering measurement on a resonant laser-driven barium plasma. J. Appl. Phys. 1985, 57, 4968-4972. [CrossRef]

122. Popović, L.Č.; Dimitrijević, M.S. Stark broadening parameters for spectral lines of singly-, doubly- and triply-charged vanadium ions. Phys. Scr. 2000, 61, 192-199. [CrossRef]

123. Popović, L.Č.; Dimitrijević, M.S.; Tankosić, D. The Stark broadening effect in hot star atmospheres: Au I and Au II lines. Astron. Astrophys. Suppl. Ser. 1999, 139, 617-623. [CrossRef]

124. Glenzer, S.; Musielok, J.; Kunze, H.J. Investigation of a pair of transition probabilities of C III in high-density plasmas. Phys. Rev. A 1991, 44, 1266-1269. [CrossRef]

125. Djeniže, S.; Srećković, A.; Bukvić, S. Experimental transition probabilities in N III, N IV and N V spectra. European Phys. J. D 2002, 20, 11-16. [CrossRef]

126. Irimia, A. Forbidden Transition Probabilities of Astrophysical Interest among Low-lying States of V III. J. Astrophys. Astron. 2007, 27, 158-166. [CrossRef] 
127. Storey, P.J.; Sochi, T. Collision strengths and transition probabilities for Co III forbidden lines. Mon. Not. R. Astron. Soc. 2016, 459, 2558-2565. [CrossRef]

128. Xu, L.H.; Persson, A.; Svanberg, S.; Blagoev, K.; Malcheva, G.; Pentchev, V.; Biémont, E.; Campos, J.; Ortiz, M.; Mayo, R. Radiative lifetime and transition probabilities in Cd I and Cd II. Phys. Rev. A 2004, 70, 042508. [CrossRef]

129. Mayo, R.; Ortiz, M.; Campos, J.; Blagoev, K.; Malcheva, G. Transition probabilities of some high lying states of Cd II. Phys. Scr. 2005, 72, 142-147. [CrossRef]

130. Çelik, G.; Erol, E.; Taşer, M. Transition probabilities, oscillator strengths and radiative lifetimes for Zn II. J. Quant. Spectrosc. Radiat. Transf. 2013, 129, 263-271. [CrossRef]

131. Nandy, D.K.; Sahoo, B.K. Relativistic calculations of radiative properties and fine structure constant varying sensitivity coefficients in the astrophysically relevant Zn II, Si IV and Ti IV ions. Mon. Not. R. Astron. Soc. 2015, 447, 3812-3823. [CrossRef]

132. Fivet, V.; Quinet, P.; Biémont, E.; Xu, H.L. Transition probabilities and lifetimes in gold (Au I and Au II). J. Phys. B 2006, 39, 3587-3598. [CrossRef]

133. Mayo, R.; Ortiz, M.; Parente, F.; Santos, J.P. Experimental and theorethical transition probabilities for lines arising from the $6 p$ configurations of Au II. J. Phys. B 2007, 40, 4651-4660. [CrossRef]

134. Tian, Y.; Wang, X.; Liu, C.; Yu, Q.; Dai, Z. Measurements of radiative lifetimes, branching fractions, transition probabilities, and oscillator strengths for Eu II and Eu III levels. Mon. Not. R. Astron. Soc. 2019, 485, 4485-4491. [CrossRef]

135. Mayo, R.; Ortiz, M.; Campos, J. Experimental oscillator strengths of Zn II lines of astrophysical interest. Eur. J. Phys. D 2006, 37, 181-186. [CrossRef]

136. Dixit, G.; Nataraj, H.S.; Sahoo, B.K.; Chaudhuri, R.K.; Majumder, S. Relativistic calculations of the lifetimes and hyperfine structure constants in ${ }^{67} \mathrm{Zn}^{+}$. J. Phys. B 2008, 41, 025001. [CrossRef]

137. Menart, J.; Heberlein, J.; Pfender, E. Line-by-Line Method of Calculating Emission Coefficients for Thermal Plasmas Consisting of Monoatomic Species. JQSRT 1996, 56, 377-398. [CrossRef]

138. Menart, J.; Heberlein, J.; Pfender, E. Theoretical Radiative Emission Results for Argon/Copper Thermal Plasmas. Plasma Chem. Plasma Process. 1996, 16, S245-S265. [CrossRef]

139. Menart, J.; Malik, S. Net emission coefficients for argon-iron thermal plasmas. J. Phys. D 2002, 35, 867-874. [CrossRef]

140. Wendt, M. Net emission coefficients of argon iron plasmas with electron Stark widths scaled to experiments. J. Phys. D 2011, 44, 125201. [CrossRef]

141. Hannachi, R.; Ben Nasr, S.; Cressault, Z.; Teulet, P.; Béji, L. Net emission coefficient of complex thermal plasmas used in SWNT synthesis. J. Phys. D 2019, 52, 095203. [CrossRef]

142. Cressault, Y.; Gleizes, A. Thermal plasma properties for Ar-Al, Ar-Fe and Ar-Cu mixtures used in welding plasmas processes: I. Net emission coefficients at atmospheric pressure. J. Phys. D 2013, 46, 415206. [CrossRef]

143. Xiang, W.; Zeng, J.; Fu, Y.; Gao, C. Detailed Theoretical Investigations on the L-Shell Absorption of Open-M-Shell Germanium Plasmas: Effect of Autoionization Resonance Broadening. J. Mod. Phys. 2012, 3, 1670-1677. [CrossRef]

144. Xiang, W.; Fu, Y.; Gao, C.; Zeng, J. Autoionization widths of open-M-shell germanium ions: Effects on inner-shell absorptions. Phys. Scr. 2012, 86, 045302. [CrossRef]

145. O'Reilly, F.; Dunne, P. 3D Photoabsorption in Zn-II, Ga-III and Ge-IV. J. Phys. B 1998, 31, 1059-1068. [CrossRef]

146. O'Reilly, F.; Dunne, P. 3D Photoabsorption in Zn-III and Ge-V. J. Phys. B 1998, 31, L141-L145. [CrossRef]

147. Zeng, J.; Dong, G.; Zhao, G.; Yuan, J. The photoionization of $\mathrm{Fe}^{7+}$ and $\mathrm{Fe}^{8+}$ in the $2 \mathrm{p}-3 \mathrm{~d}$ resonance energy region. J. Phys. B 2004, 37, 2529-2542. [CrossRef]

148. Zeng, J.; Yuan, J.; Lu, Q. Photoionization of O III low-lying states: Autoionization resonance energies and widths of some 1s-2p excited states. J. Phys. B 2001, 34, 2823-2833. [CrossRef]

149. Comet, M.; Gosselin, G.; Meot, V.; Morel, P.; Pain, J.-C. Nuclear excitation by electron transition rate confidence interval in a ${ }^{201} \mathrm{Hg}$ local thermodynamic equilibrium plasma. Phys. Rev. C 2015, 92, 054609. [CrossRef]

150. Maslov, M.; Brunger, M.J.; Teubner, P.J.O.; Zatsarinny, O.; Bartschat, K.; Fursa, D.; Bray, I.; McEachran, R.P. Electron-impact excitation of the $\left(5 d^{10} 6 s\right)^{2} S_{1 / 2}-\left(5 d^{10} 6 p\right)^{2} P_{1 / 2,3 / 2}$ resonance transitions in gold atoms. Phys. Rev. A 2008, 77, 062711. [CrossRef] 
151. Mihajlov, A.A.; Srećković, V.A.; Ignjatović, L.M.; Klyucharev, A.N. The Chemi-Ionization Processes in Slow Collisions of Rydberg Atoms with Ground State Atoms: Mechanism and Applications. J. Clust. Sci. 2012, 23, 47-75. [CrossRef]

152. Brunner, W.; Ritze, H.H. Conditions for XUV Amplification Considering Recombination in Clusters. Appl. Phys. B 1998, 67, 47-51. [CrossRef]

153. Bakshi, V.; Barrett, B.D.; Boone, T.D., Jr.; Nunnally, W.C. Spectroscopic diagnostics of railgun plasma armatures. IEEE Trans. Magn. 1993, 29, 1097-1101. [CrossRef]

154. Wetzler, H.; Suss, W.; Stockl, C.; Tauschwitz, A.; Hoffmann, D.H.H. Density Diagnostics of an Argon Plasma by Heavy-Ion Beams and Spectroscopy. Laser Part. Beams 1997, 15, 449-459. [CrossRef]

155. Konjević, N. On the use of non-hydrogenic spectral line profiles for plasma electron density diagnostics. Plasma Source Sci. Technol. 2001, 10, 356-363. [CrossRef]

156. Ivković, M.; Jovićević, S.; Konjević, N. Low electron density diagnostics: Development of optical emission spectroscopic techniques and some applications to microwave induced plasmas. Spectrochim. Acta B 2004, 59, 591-605. [CrossRef]

157. Cheron, B.G.; Bultel, A.; Delair, L. Experimental study of a double arc nitrogen plasma: Static and dynamic behavior. IEEE Trans. Plasma Sci. 2007, 35, 498-508. [CrossRef]

158. Jovović, J.; Stojadinović, S.; Šišović, N.M.; Konjević, N. Spectroscopic characterization of plasma during electrolytic oxidation (PEO) of aluminium. Surf. Coat. Technol. 2011, 206, 24-28. [CrossRef]

159. Antonov, O.; Efimov, S.; Gurovich, V.T.; Bernshtam, V.; Krasik, Y.E. Spectroscopy of a plasma formed in the vicinity of implosion of the shock wave generated by underwater electrical explosion of spherical wire array. Phys. Plasmas 2015, 22, 053507. [CrossRef]

160. Ehrich, H.; Kaplan, J.; Muller, K.G. Initiation of arcing at a plasma-wall contact. IEEE Trans. Plasma Sci. 1986, 14, 603-608. [CrossRef]

161. Heading, D.J.; Machacek, A.; Whitford, L.C.; Varney, A.J.; Wark, J.S.; Lee, R.W.; Stamm, R.; Talin, B. Rapid generation of approximate optical spectra of dense cool plasmas. J. Quant. Spectrosc. Radiat. Transf. 1997, 58, 619-626. [CrossRef]

162. Ghebregziabher, I.; Hartig, K.C.; Jovanovic, I. Propagation distance-resolved characteristics of filament-induced copper plasma. Opt. Express 2016, 24, 5263-5276. [CrossRef]

163. Pandey, P.K.; Thareja, R.K.; Costello, J.T. Heterogeneous (Cu-Ti) colliding plasma dynamics. Phys. Plasmas 2016, 23, 103516. [CrossRef]

164. Nagai, H.; Kikuchi, R.; Inada, Y.; Matsuoka, S.; Shioiri, T.; Kumada, A.; Hidaka, K. Process of Vacuum Breakdown between $\mathrm{Cu}$ and $\mathrm{CuCr}$ Electrodes. IEEE Trans. Plasma Sci. 2019, 47, 5191-5197. [CrossRef]

165. Garkusha, I.E.; Chebotarev, V.V.; Solyakov, D.G.; Petrov, Y.V.; Ladygina, M.S.; Marchenko, A.K.; Staltsov, V.V.; Yelisyeyev, D.V. Compression zone of a magnetoplasma compressor as a source of extreme UV radiation. Plasma Phys. Rep. 2012, 38, 110-115. [CrossRef]

166. Milosavljević, V.; Poparić, G. Atomic spectral line free parameter deconvolution procedure. Phys. Rev. E 2001, 63, 036404. [CrossRef] [PubMed]

167. Dimitrijević, M.S.; Chougule, A. Stark broadening of Cr III spectral lines: DO white dwarfs. Atoms 2018, 6, 15. [CrossRef]

168. Abdul Rahim Yaqub, N.; Qindeel, R.; Alonizan, N.; Ben Nessib, N. Expectation Values of the Neutral Chromium Radius. Atoms 2018, 6, 51. [CrossRef]

169. Dimitrijević, M.S.; Sahal-Bréchot, S. On the Application of Stark Broadening Data Determined with a Semiclassical Perturbation Approach. Atoms 2014, 2, 357-377. [CrossRef]

170. Dimitrijević, M.S.; Sahal-Bréchot, S.; Moreau, N. The STARK-B Database, a Node of Virtual Atomic and Molecular Data Center (VAMDC). Publ. Astron. Obs. Belgrade 2018, 98, 285-288.

171. Sahal-Bréchot, S.; Dimitrijević, M.S.; Moreau, N. Virtual Laboratory Astrophysics and the STARK-B database VAMDC node: A resource for electron and ion impact widths and shifts of isolated lines. J. Phys. Conf. Ser. 2020, 1412, 132052. [CrossRef]

172. Dubernet, M.L.; Boudon, V.; Culhane, J.L.; Dimitrijević, M.S.; Fazliev, A.Z.; Joblin, C.; Kupka, F.; Leto, G.; Le Sidaner, P.; Loboda, P.A.; et al. Virtual atomic and molecular data centre. J. Quant. Spectrosc. Radiat. Transf. 2010, 111, 2151-2159. [CrossRef] 
173. Dubernet, M.L.; Antony, B.; Ba, Y.A.; Babikov, Y.; Bartschat, K.; Boudon, V.; Braams, B.; Chung, H.K.; Daniel, F.; Delahaye, F.; et al. The Virtual Atomic and Molecular Data Centre (VAMDC) Consortium. J. Phys. B At. Mol. Opt. Phys. 2016, 49, 074003. [CrossRef]

174. VAMDC Portal. Available online: https://portal.vamdc.eu (accessed on 20 July 2020).

(C) 2020 by the author. Licensee MDPI, Basel, Switzerland. This article is an open access article distributed under the terms and conditions of the Creative Commons Attribution (CC BY) license (http://creativecommons.org/licenses/by/4.0/). 